\title{
ВНУТРЕННИЙ ФИНАНСОВЫЙ КОНТРОЛЬ: ПОНЯТИЕ, ВИДЫ И НЕОБХОДИМОСТЬ ПРОВЕДЕНИЯ В РАМКАХ РАСХОДОВАНИЯ СРЕДСТВ НА ФЕДЕРАЛЬНЫЕ ПРОЕКТЫ
}

\author{
(C) 2020 Петров А.M. \\ доктор экономических наук, профессор Департамента бизнес-аналитики \\ Финансовый университет при Правительстве Российской Федерации, Россия, Москва \\ E-mail:palmi@inbox.ru \\ (C) 2020 Бердникова Л.Ф. \\ кандидат экономических наук, доцент департамента магистратуры (бизнес-программ) \\ Тольяттинский государственный университет, Россия, Тольятти \\ E-mail: bleylaf@mail.ru \\ (C) 2020 Гордова М. А. \\ кандидат экономических наук, \\ старший преподаватель Департамента аудита и корпоративной отчетности \\ Финансовый университет при Правительстве Российской Федерации, Россия, Москва \\ E-mail: MGordova@fa.ru
}

Современные условия сопряжены с ростом различной внешней и внутренней экономической информации, которая для пользователей выступает основным и важным источником для принятия обоснованных управленческих решений. Таким образом, растет потребность в действенном финансовом контроле за полнотой и достоверностью учетно-отчетной экономической информации. С ужесточением конкуренции, возникновением внешних угроз, неопределенностью влияния экзогенных и эндогенных факторов необходим детальный контроль, выявляющий основные причины разбалансированности отдельных субъектов финансовой системы с целью совершенствования инструментов для устранения такого дисбаланса. Для решения данной задачи необходимы четкие требования к финансовому контролю, развитие инструментария его проведения как с позиции распределителей бюджетных средств, так и их получателей. Анализ практики показал, что наиболее разумным и действенным является не устранение последствий нарушений, а их оперативное предотвращение. Следовательно, повышается роль оперативного и превентивного финансового контроля в рамках расходования средств на федеральные проекты. Отсюда возникает необходимость в первую очередь в совершенствовании теоретического аппарата, а в последующем и методического инструментария финансового контроля в целях предотвращения различных нарушений, связанных с расходованием средств при исполнении федеральных проектов. Оперативное выявление нарушений будет способствовать недопущению негативных последующих последствий. А превентивные мероприятия должны быть нацелены на опережающее выявление рисков возникновения таких нарушений. В комплексе применение различных видов финансового контроля будет способствовать предупреждению финансовых махинаций как на макро- и микроуровнях. В статье раскрыто понятие внутреннего финансового контроля применительно к расходованию средств в рамках реализации федеральных проектов. Существенное внимание уделено видам финансового контроля. В частности, раскрыты такие виды финансового контроля как внутренний и внешний, оперативный и превентивный при расходовании средств на федеральные проекты. В статье обоснована необходимость проведения внутреннего финансового контроля при расходовании денежных средств в рамках реализации федеральных проектов как с позиции распределителей бюджетных средств, так и с позиции их получателей.

Ключевые слова: контроль, финансовый контроль, виды финансового контроля, внутренний финансовый контроль, внешний финансовый контроль, государственный контроль, расходование средств, федеральные проекты, бюджетные средства, расходы, бюджет, распределители средств, получатели средств

\footnotetext{
* Статья подготовлена по результатам исследований, выполненных за счет бюджетных средств по государственному заданию Финансового университета
} 
В современных условиях сохраняется разобщенность систем внешнего и внутреннего контроля и полномочий контрольных органов и организационно-методических основ их взаимодействия. В результате несогласованности одни объекты контроля подвергаются пристальному вниманию со стороны контрольных органов, в то время как иные объекты выпадают из сферы контрольных проверок. При этом проверки осуществляются по разной методике и могут приводить к противоречивым результатам. Кроме этого, нерешенными остаются проблемы недостаточной действенности мер ответственности за нарушения при расходовании средств на федеральные проекты.

Критический анализ существующих концепций финансового контроля установил отсутствие в них целевых установок по устранению предпосылок вероятности появления нарушений при расходовании средств при исполнении федеральных проектов, целей системы управления, системы категорий, научно-практического инструментария. Все вышеперечисленное определило необходимость в совершенствовании понятийного аппарата и методического инструментария финансового контроля в рамках расходования средств на федеральные проекты.

Государственный финансовый контроль регулируется многими нормативными документами [1-10]. Значительный вклад в развитие финансового контроля и аудита внесли такие известные ученые как Р.П.Булыга, Л.И.Воронина, Ю.В.Гнездова, И.С.Егорова, А.М.Петров, Г. А. Скачко, В. П. Суйц, А. Д.Шеремет и др. [11-20]. Тем не менее, в современных условиях актуальным становится проблемы финансового контроля в рамках расходования средств на федеральные проекты.

В целях контроля за движением денежных потоков особое значение приобретает финансовый контроль.

Проведенное исследование установило, что несмотря на достаточную изученность понятия «внутренний финансовый контроль» в научной литературе его содержание недостаточно раскрыто при расходовании средств в рамках выполнения федерального проекта.

В правовой доктрине среди целей финансового контроля выделено несколько точек зрения. Одни авторы указывают, что целью финансового контроля является обеспечение законности и целесообразности проводимой финансовой деятельности. По мнению других авторов, цель финансового контроля заключается в обеспечении законности в финансовой и хозяйственной деятельности, а также предотвращение актов бесхозяйственности и расточительности [17]. Среди распространенных взглядов, можно встретить позицию, при которой целью финансового контроля является проверка законности и обоснованности финансовых операций по формированию доходов государства, осуществлению его расходов, эффективному управлению государственной собственностью, контроль выполнения соответствующими субъектами установленных форм финансовых отношений и соответствия всех процессов финансовой политике проводимой государством.

Исходя из приведенных определений считаем, что цель финансового контроля в финансово-бюджетной сфере состоит в обеспечении целевой направленности, законности, эффективности и экономической обоснованности финансовой деятельности государства. Для достижения данной цели следует решать задачи, направленные на:

- установление соответствия формирования и потребления бюджетных средств нормативным правовым актам и локальным документам проверяемых субъектов;

- оценку эффективности использования средств на федеральные проекты;

- предотвращение нарушений в сфере финансово-бюджетного законодательства;

- предупреждение финансовых нарушения расходования средств на федеральные проекты;

- применение к нарушителям мер финансово-правовой ответственности.

«Концептуальные основы внутреннего контроля в работах российских ученых позволяют определить его как подсистему управления организацией, ориентированную на результат управления финансами посредством инструментов контроля, с целью обеспечения непрерывного потока внутренней и внешней информацией для разработки и принятия обоснованных управленческих решений» [16].

Считаем, что внутренний финансовый контроль при расходовании средств в рамках выполнения федеральных проектов представляет собой совокупность методов и процедур, направленных на определение правомерности расходования средств по целевому назначению, оценку соответствия деятельности субъекта хо- 
зяйствования в области управления денежными потоками нормам, установленным законодательством, государственным заданием, бюджеTOM.

Необходимо отметить, что финансовые нарушения при расходовании средств могут негативным образом повлиять не только на отдельно функционирующий экономический субъект, но и на выполнение государственно значимых проектов. Следовательно, роль контрольных процедур, методик, используемых при внутренних финансовых проверках, существенно повышается, особенно в части расходования средств, выделенных из бюджета при выполнения федеральных проектов.

Рассмотрим основные аспекты классификации финансового контроля как в целом, так и применительно к операциям, связанным с выполнением федеральных проектов.

Базовой составляющей государственного управления выступает государственный финансовый контроль. Его подразделяют на внешний государственный (муниципальный) финансовый контроль и внутренний государственный (муниципальный) финансовый контроль.

С позиции экономического субъекта на микроуровне финансовый контроль подразделяется на внешний и внутренний. Внешней производится внешними специалистами при выполнении профессиональных обязанностей и должностных функций. Внутренний финансовый контроль осуществляется внутренними силами субъектов хозяйствования, то есть штатным персоналом.

Остановимся более подробно на видах внутреннего финансового контроля. Важной классификацией внутреннего финансового контроля является его подразделение на предварительный, текущий и последующий. Четкую границу между предварительным и текущим контролем установить достаточно сложно, учитывая тенденцию к объединению в законодательстве предварительного и текущего контроля, которая прослеживается в отдельных документах. Их примером может выступать в действующей редакции Бюджетный Кодекс РФ, в котором закреплено только две формы контроля:

- предварительный;

- последующий.

На уровне отдельного субъекта выделяют такие виды внутреннего финансового контроля как:
- предварительный;

- оперативного;

- последующий.

Ввиду того, что основной целью внутреннего финансового контроля является предупреждение нарушений, что выделяет такой его вид как превентивный. При этом, превентивные основные мероприятия должны проводиться как в процессе реализации предварительного контроля, так и оперативного.

Превентивный внутренний финансовый контроль представляет собой контроль, направленный на предотвращение нарушений, искажений и ошибок. Соответственно, к основным методам превентивного внутреннего финансового контроля в рамках расходования средств на федеральные проекты необходимо отнести: анализ, обследование, мониторинг, проверку и др.

Внутренний оперативный финансовый контроль направлен на обеспечение обратной связи между прогнозными показателями, определенными первоначальными планами и фактическими данными, полученными в результате выполнения проектов. Он должен реализоваться на протяжении всего периода выполнения федеральных проектов как с позиции распределителей бюджетных средств, так и их получателей.

K основным методам оперативного внутреннего финансового контроля в рамках расходования средств на федеральные проекты необходимо отнести: анализ, индукцию, дедукцию, обследование, мониторинг, проверку, опрос, тестирование и др. Необходимо отметить, что данные методы могут применяться как распорядителями, так и получателями средств в рамках расходования средств на федеральные проекты.

Под процедурами внутреннего финансового контроля следует понимать действия, направленные на минимизацию и нейтрализацию рисков, влияющих на достижение целей и задач при реализации федеральных проектов.

Превентивный и оперативный внутренний финансовый контроль являются важными не только для выявления основных нарушений расходования средств и иных неправомерных действий, но и для своевременного принятия решения по их устранению.

Последующий внутренний финансовый контроль может лишь зафиксировать факт правонарушения, но не может обеспечить его устранение во время работы и освоения. 
Таким образом, система эффективного финансового контроля (внутреннего) должно предполагать:

- принятие соответствующих локальных актов, закрепляющих ответственность за расходование федеральных средств;

- определение сроков внутренних проверок по операциям, связанным с расходованием средств при выполнении федеральных проектов;

- обеспечение открытой и прозрачной информации по движению денежных средств, направленных на реализацию федеральных проектов при оперативном запросе контрольными органами и др.

Подводя итог, можно отметить, что внутренний финансовый контроль выступает одним из основных мер, решающих задачи оперативного управлением денежными потоками при выполнении федеральных проектов. В свою очередь, оперативный финансовый контроль обеспечивает систему управления необходимой текущей информацией, а превентивный позволяет предотвратить возможные нарушения и действует на опережение, что в конечном результате способствует эффективному выполнению государственных заданий.

\section{Библиографический список}

1. Бюджетный кодекс Российской Федерации от 31.07.1998 № 145-Ф3 (ред. от 01.10.2020 г.)

2. Уголовный кодекс Российской Федерации от 13.06 .1996 г. № 63-Ф3 (в ред.31.07.2020 г.)

3. Федеральный закон от 05.04.2013 г. № 44-Ф3 «О контрактной системе в сфере закупок товаров, работ, услуг для обеспечения государственных и муниципальных нужд» (в ред. от 31.07.2020 г.)

4. Федеральный закон от 07.08.2001 г. № 115-Ф3 «О противодействии легализации (отмыванию) доходов, полученных преступным путем и финансированию терроризма» (в ред. от 20.07.2020 г.)

5. Федеральный закон от 25.12.2008 г. № 273-Ф3 «О противодействии коррупции» (в ред. от 24.04.2020 г.)

6. Федеральный закон от 26.07.2019 № 199-Ф3 «О внесении изменений в Бюджетный кодекс Российской Федерации в части совершенствования государственного (муниципального) финансового контроля, внутреннего финансового контроля и внутреннего финансового аудита»

7. Распоряжение Мособлконтроля от 26.05.2017 № 8-р «О Классификаторе нарушений, выявляемых в ходе осуществления внутреннего государственного финансового контроля и контроля в сфере закупок» (ред. от 20.06.2019).

8. Международный стандарт аудита 315 (пересмотренный) «Выявление и оценка рисков существующего искажения посредством изучения организации и ее окружения» (введен в действие на территории РФ Приказом Минфина России от 09.01.2019 г.)

9. Международный стандарт аудита 610 (пересмотренный, 2013 г.) «Использование работы внутренних аудиторов» введен в действие на территории РФ Приказом Минфина России от 09.01.2019 г.)

10. Информация Минфина России N П3-11/2013 «Организация и осуществление экономическим субъектом внутреннего контроля совершаемых фактов хозяйственной жизни, ведения бухгалтерского учета и составления бухгалтерской (финансовой) отчетности»

11. Булыга Р.П.Инновационные направления и процедуры аудита и контроля: учебник для студентов вузов, обучающихся по направлению подготовки «Экономика».- ЮНИТИ, 2018. - 159 с.

12. Воронина Л. И. Аудит: теория и практика. В 2 ч. Ч.2. Практический аудит: учебник.- Инфра-М, 2018. - 343 с.

13. Гнездова Ю. В. Государственный аудит в системе финансового контроля: учебник для магистрантов.- ЮНИТИ, 2017.- 151 с.

14. Егорова И. С. Аудит: учебное пособие.-КНОРУС, 2017. - 537 с.

15. Петров А.М. К вопросу организации внутреннего финансового контроля в рамках расходования средств на федеральные проекты/ А. М. Петров, К. Ю. Бурцева // Экономические науки, 2020, № 7 (188). С. 113-119.

16. Петров А.М. Оперативный и превентивный инструментарий реализации внутреннего финансового контроля в рамках расходования средств на федеральные проекты/ А. М.Петров// Экономические науки, 2020, № 4 (185). С. 169-178.

17. Правовое регулирование финансового контроля в Российской Федерации: проблемы и перспективы: Монография / Отв. ред. Е. Ю. Грачева.- М.: Норма, 2013.

18. Петров А.М. «КОНТРОЛЬ ЗА ДВИЖЕНИЕМ ДЕБИТОРСКОЙ И КРЕДИТОРСКОЙ ЗАДОЛЖЕННОСТИ» Современный бухучет. 2004. № 9. С. 38. 
19. Карпова Т.П., Петров А.М., ГорбатковаГ.А., СамаринаЛ.Б., ДашкинаГ.Г., СидороваМ.И., Сабанин Р.Л., Ситникова В.А., ЛистопадЕ.Е. «БУХГАЛТЕРСКИЙ УЧЕТ В СФЕРЕ УСЛУГ» учебник для студентов высшего профессионального образования, обучающихся по специальности 080109 «Бухгалтерский учет, анализ и аудит» / Под редакцией М.А. Вахрушиной; Министерство образования и науки Российской Федерации, Федеральное государственное учреждение «Федеральный институт развития образования». Москва, 2011. Сер. Читай

20. Петров А.М., МельниковаЛ.А. «ФОРМИРОВАНИЕ ОТЧЕТНОСТИ В СООТВЕТСТВИИ С ТРЕБОВАНИЯМИ МСФО КАК ОБЪЕКТИВНАЯ НЕОБХОДИМОСТЬ НА СОВРЕМЕННОМ ЭТАПЕ РАЗВИТИЯ ЭКОНОМИКИ РФ» Проблемы современной экономики. 2017. № 2 (62). С. 105-107.

21. Петров А.М., Коняхин А.Н. «УЧЕТНАЯ ПОЛИТИКА ПРИ ПОДГОТОВКЕ ПЕРВОЙ ОТЧЕТНОСТИ СОГЛАСНО МСФО» Международный бухгалтерский учет. 2013. № 11 (257). С. 2-15.

22. Петров А.М., Лымарь М. П. «СОСТАВ БУХГАЛТЕРСКОЙ ОТЧЕТНОСТИ В РОССИИ И КИТАЕ» МежДУнароднЫЙ бухгалтерский учет. 2014. № 31 (325). С. 28-37.

23. Петров А.М., Лымарь М.П. «СРАВНИТЕЛЬНАЯ ХАРАКТЕРИСТИКА ОСНОВНЫХ ПОЛОЖЕНИЙ ЗАКОНОВ, РЕГУЛИРУЮЩИХ БУХГАЛТЕРСКИЙ УЧЕТ В КИТАЕ И РОССИИ» МеждународныЙ бухгалтерскиЙ учет. 2013. № 40 (286). С. 52-60.

24. Петров А.М., Лымарь М.П. «СРАВНИТЕЛЬНЫЙ АНАЛИЗ БУХГАЛТЕРСКОГО УЧЕТА АКТИВОВ В РОССИИ И КИТАЕ» Международный бухгалтерский учет. 2014. № 27 (321). С. 34-48.

25. Петров А.М. «ОБЩЕСТВЕННОЕ ПИТАНИЕ 6 в 1: учетная политика, документооборот, калькулирование себестоимости, бухгалтерский учет, налоги, отчетность» / А. М.Петров. Москва, 2011. Сер. Полное руководство бухгалтера

26. Скачко Г. А. Аудит: учебник.-Дашков и К, 2017. - 299 с.

27. Суйц В. П. Аудит: учебник. - КНОРУС, 2017. - 287 с.

28. Шеремет А. Д. Аудит: учебник.-ИНФРА-М.-2017.- 375 с. 